\title{
Commentary Acute respiratory failure in the elderly
} Jean-Yves Fagon

Hôpital Européen Georges Pompidou, Assistance Publique - Hôpitaux de Paris and Faculté René Descartes Paris 5, Paris, France

Corresponding author: Jean-Yves Fagon, jean-yves.fagon@egp.aphp.fr

Published: 25 July 2006

This article is online at http://ccforum.com/content/10/4/151

(c) 2006 BioMed Central Ltd

See related research by Ray et al., http://ccforum.com/content/10/3/R82
Critical Care 2006, 10:151 (doi:10.1186/cc4982)

Emergency Room not in the ICU, and was conducted in a global geriatric population including patients aged $<70$ years as well as patients aged $>85$ years who basically have different prognoses and raise different diagnostic and therapeutic problems.

Ray and colleagues' study is important as it presents epidemiologic data based on more than 10,000 elderly patients in the Emergency Room, including 514 patients with ARF [5]. Twenty-nine per cent of ARF patients required ICU admission during the first 24 hours; a missed diagnosis was retrospectively noted in $20 \%$ of cases. An inappropriate treatment, prescribed in $32 \%$ of patients, was associated with an increased mortality rate (25\% versus $11 \%$ in patients correctly treated in the Emergency Room). The authors suggested systematically evaluating the severity of illness of such elderly patients with ARF using easy-to-obtain criteria: $\mathrm{PaCO}_{2}$, creatinine clearance, the brain natriuretic peptide levels and the presence of abdominal paradoxical respiration (or the use of accessory respiratory muscles) were identified as variables independently associated with death.

Studies conducted in geriatric patients for more than 25 years are not without limitations and possible drawbacks, particularly when they evaluate the impact of advancing age on outcomes [6]. First, these studies were conducted in groups of patients with non-generally accepted definitions of patients arbitrarily called old, young-old, very old, or oldestold patients $(>65$ years, $>70$ years, $>75$ years, $>80$ years, $>85$ years, $>90$ years). The studied patients were usually compared with totally different control groups: younger patients, or younger patients with the same disease or syndrome, or same-age patients without critical illness. A third limitation is that the procedures used during the hospital stay and/or the ICU stay were not always considered. Fourth, because of variations in culture, demographics and allocation of resource systems resulting in large variations in admission

$\mathrm{ARF}=$ acute respiratory failure $\mathrm{ICU}=$ intensive care unit. 
policy, because of preferences for life-sustaining therapies and because of decisions to withhold such therapies and donot-resuscitate orders, the results were difficult to generalize. In addition, as for all studies conducted in populations of severely ill elderly patients, a selection bias cannot be eliminated in this study, with probably only the oldest-old patients in good condition being admitted [3].

The relatively high rate of missed diagnosis is not surprising. Twenty years ago, Bayer and colleagues identified, in a large unselected group of elderly patients, the variable presentation of acute myocardial infarction [7]. In extreme old age (>85 years), atypical symptoms become the rule and the clinician must be prepared to screen for the diagnosis in most acutely ill patients. Riquelme and colleagues similarly demonstrated that community-acquired pneumonia in the elderly has a different clinical presentation to communityacquired pneumonia in other age groups. This incomplete presentation with a concomitant delay in antimicrobial treatment may contribute to the greater mortality of community-acquired pneumonia in the elderly compared with younger patients [8].

Diseases therefore have atypical presentations in the geriatric population, and the diagnostic and therapeutic management of elderly patients should consider the multisystem involvement often present in the development of disease in such patients. We should be committed to many more clinical trials and evaluations of diagnostic and management procedures as applied in the elderly to try to define 'realistic' goals. These procedures should include adequate follow-up observation so that we can judge from the outcome what has been beneficial and what has been useless [9].

Numerous studies on the outcomes of critically ill elderly patients have been published in recent years. Briefly, three types of criteria, frequently measured at the same time in the same cohort of patients, are used to define geriatric critical care outcomes: short-term mortality (hospital mortality, ICU mortality, 30-day mortality, etc.), long-term mortality (90-day mortality, 1-year mortality, 3-year mortality, etc.) and quality of life (functional status, measures of activities, etc.). The large majority of these studies indicated that acute physiology disturbances and diagnosis had much larger relative contributions to short-term prognosis than age. After adjusting for important prognostic factors including severity of acute illness, underlying comorbidities and preadmission functional status, age was identified as accounting for less than $5 \%$ of the explanatory power for hospital mortality $[10,11]$.

Short-term survival of patients older than 65 years, however, is significantly lower than that for younger patients. Also, in a population of critically ill elderly patients, a significant relationship exists between age and inhospital mortality. Finally, after discharge from the hospital, deaths occurred predominantly during the first 3 months [12]. Unlike the secondary importance of age on short-term mortality, age per se is a risk factor for long-term mortality - the risk of death increasing with the number of comorbidities, a low cognitive function and the difficulty in instrumental activity. It is worthy of notice that patients surviving 1 year after ICU admission had regained their previous health status and their further survival almost paralleled than that of the general population [13].

Although Ray and colleagues' study of ARF in the elderly is limited to the Emergency Room setting and cannot be directly extrapolated to the critical care unit, it raises a number of important questions that are very relevant to the ICU setting. Additional research in the ICU also does not support the rationing of healthcare based on chronological age. Physicians tend to overestimate the importance of age in survival from critical illness, and they underestimate the quality of life for elderly survivors. To avoid an inappropriate utilization of ICUs for the elderly, particularly the oldest-old patients ( $>85$ years), admission policies must be better defined. To date, the data underscore the need to develop accurate risk prediction formulas: we need to identify during the early phase of their critical illness those elderly patients who may benefit from intensive care. Finally, studies evaluating long-term outcomes, including quality of life and costs, are needed so that patients, families and physicians can make decisions based on expected outcomes and patient/family wishes.

\section{Competing interests}

The author declares that they have no competing interests.

\section{References}

1. Hobbs F, Damon BL, Taeuber CM: Sixty-five Plus in the United States. Washington, DC: US Department of Commerce, Economics, and Statistics Administration, Bureau of the Census; 1996.

2. Yu W, Ash AS, Levinsky NG, Moskowitz MA: Intensive care unit use and mortality in the elderly. J Gen Intern Med 2000, 15:97102.

3. Boumendil A, Aegerter P, Guidet B, CUB-Rea Network: Treatment intensity and outcome of patients aged 80 and older in intensive care units: a multicenter matched-cohort study. J Am Geriatr Soc 2005, 53:88-93.

4. Behrendt CE: Acute respiratory failure in the United States: incidence and 31-day survival. Chest 200, 118:1100-1105.

5. Ray $P$, Birolleau S, Lefort $Y$, Becquemin $M H$, Beigelman $C$, Isnard $\mathrm{R}$, Teixeira A, Arthaud M, Riou B, Boddaert J: Acute respiratory failure in the elderly: etiology, emergency diagnosis and prognosis. Crit Care 2006, 10:R82.

6. Chelluri L, Grenvik A Silverman M: Intensive care for critically elderly: mortality, costs, and quality of life. Review of the literature. Arch Intern Med 1995, 155:1013-1022.

7. Bayer AJ, Chadha JS, Farag RR, Pathy MSJ: Changing presentation of myocardial infarction with increasing old age. $J \mathrm{Am}$ Geriatr Soc 1986, 34:263-266.

8. Riquelme R, Torres A, El Ebiary M, Mensa J, Estruch R, Ruiz M, Angrill J, Soler N: Community-acquired pneumonia in the elderly. Clinical and nutritional aspects. Am J Respir Crit Care Med 1997, 156:1908-1914.

9. Rosenthal RA, Kavic SM: Assessment and management of the geriatric patient. Crit Care Med 2004, 32:S92-S105.

10. Knaus WA, Draper EA, Wagner DP, Zimmerman JE: APACHE II: a severity of disease classification system. Crit Care Med $1985,13: 818-829$. 
11. Rockwood K, Noseworthy TW, Gibney RT, Konopad E, Shustack A, Stollery D, Johnston R, Grace M: One-year outcome of elderly and young patients admitted to intensive care units. Crit Care Med 1993, 21:687-691.

12. Somme D, Maillet D, Gisselbrecht M, Novara A, Ract C, Fagon $\mathrm{J}-\mathrm{Y}$ : Critically ill old and the oldest-old patients in intensive care: short- and long-term outcomes. Intensive Care Med 2003, 29:2137-2143.

13. Campion EW, Mulley AG, Goldstein RL, Barnett GO, Thibault GE: Medical intensive care for the elderly. A study of current use, costs, and outcomes. JAMA 1981, 246:2052-2056. 